\title{
Fuzzy Logic Implementation to Control Temperature and Humidity in a Bread Proofing Machine
}

\author{
${ }^{1}$ Aulia Ullah, ${ }^{2}$ Oktaf Brillian Kharisma, ${ }^{3}$ Imam Santoso, \\ 1,2,3 Departement of Electrical Engineering, State Islamic University of Sultan Syarif Kasim Riau \\ 11 aulia.ullah@uin-suska.ac.id, ${ }^{2}$ brilliankhar@gmail.com, ${ }^{3}$ imam.santoso@ students.uin-suska.ac.id
}

\begin{tabular}{l}
\hline \hline Article Info \\
\hline Article history: \\
Received Aug 1 \\
Revised Sep 10 \\
Accepted Sep 3 \\
\\
\hline Keyword: \\
Bread Proofing \\
Fuzzy Logic \\
Heater \\
Evaporator \\
Humidity \\
Temperature
\end{tabular}

Corresponding Author:

Aulia Ullah

Department of Electrical Engineering

Faculty of Science and Technology

State Islamic University of Sultan Syarif Kasim Riau

Soebrantas 155 Pekanbaru - Indonesia

Email: aulia.ullah@uin-suska.ac.id

\begin{abstract}
Factors that need to be considered of producing good quality bread are raw materials, balance formulas (recipes) and production processes. The bread dough that cannot proof perfectly has become a problem in the process of bread production. Therefore, the temperature and humidity of the room must be controlled at a certain temperature range. The solution of this problem is proposing a controller that uses Fuzzy logic to control temperature and humidity in the bread examination room. A bread proofing machine is added a controller such as evaporator that it is can controlled the temperatur and humidity automatically. The heat and steam produced are regulated using a Fuzzy logic algorithm embedded in the microcontroller with a predetermined set point of temperature and humidity is $35^{\circ} \mathrm{C}$ and $80 \%$. The test is done by determining the percentage error from the temperature and humidity test results, that is when the machine is free of load obtained the percentage error to set points is $0,429 \%$ and 0,937 $\%$. While the engine is loaded. It gives the results are $0,024 \%$ and $0,015 \%$. The results of this test prove that controlling temperature and humidity in a bread proofing machine using Fuzzy logic can provide good results compared to conventional controllers. as a result, the bread mixture can expand uniformly.
\end{abstract}

Copyright $@ 2018$ Puzzle Research of Data Technology

\section{PENDAHULUAN}

Tren konsumsi bahan pangan di Indonesia meningkat seiring terjadinya peningkatan jumlah penduduk[1]. Saat ini konsumsi daging, produk berbasis susu dan makanan siap saji yang termasuk roti semakin lazim di Indonesia [2]. Mengonsumsi roti dianggap lebih praktis bagi pola hidup masyarakat perkotaan yang cenderung sibuk dan aktif. [3]. Konsumsi roti masyarakat Indonesia beberapa tahun belakangan rata-rata per kapita-0,72 \% [4], namun di rentang waktu yang sama jumlah penduduk Indonesia terjadi peningkatan sekitar rata-rata $1,5 \%$ per tahun[5]. Nilai negatif menunjukkan pertumbuhan penduduk tidak sebanding dengan pertumbuhan industri roti dalam memenuhi kebutuhan. Konsumsi Roti tahun 2010-2014 mengalami peningkatan 14,3\% dan diproyeksikan tahun 2015-2020 naik 10\% [2].

Untuk menjaga kualitas roti terjaga dengan baik, beberapa faktor yang harus diperhatikan. Secara umum ada 3 faktor yang mempengaruhi kualitas roti, yaitu bahan baku, keseimbangan formula (resep), dan proses produksi [6][7][8]. Permasalahan yang sering terjadi pada proses produksi roti adalah adonan tidak mengembang dengan baik. Untuk mendapatkan hasil pengembangan adonan roti yang sempurna, maka proses pengadukan adonan dan proses pengembangan roti (proofing) akhir harus diperhatikan [9]. Untuk menghasilkan adonan roti yang mengembang seragam dalam arti adonan roti dalam ruang proofing roti mengembang semua, maka diperlukan pengendalian suhu dan kelembaban pada ruang proofing [10]. Pengendalian suhu adonan perlu dilakukan agar konstan untuk memastikan konsistensi kualitas produk. Jika suhu adonan dinaikkan terlalu tinggi maka akan menjadi terlalu lunak untuk diproses. Jika suhu adonan terlalu 
rendah, maka adonan menjadi kaku dan kerusakan pada adonan akan meningkat[11]. Pada proses proofing, adonan roti akan mengembang dengan baik pada rentang suhu $27-40{ }^{\circ} \mathrm{C}$ dengan kelembaban $75-85 \%$ [12][13]

Tantangan dalam membangun pengendali dalam pemrosesan makanan, beberapa diantaranya proses pembuatan makanan memiliki banyak parameter, bahan baku yang digunakan tidak seragam, prosesnya yang non linier, dan tidak banyak data yang tersedia yang dapat digunakan untuk data awal perancangan pengendali[14]. Selain itu dalam sistem makanan dan kesulitan khusus untuk menemukan hubungan sebabakibat yang unik yang disebabkan oleh material dan proses non linearitas menyebabkan kompleksitas besar sistem pangan. Kebanyakan pendekatan yang cukup menjanjikan adalah pendekatan yang meniru adaptasi dalam sistem alami dengan mentransfernya secara komputasi ke sistem buatan[15].

Kendali logika Fuzzy mampu mengenali variabilitas ketika proses memasak, misal kecepatan dan suhu udara. Fuzzy mampu memprediksi waktu proses yang diperlukan dan prediksi ketika penyesuaian proses perlu dilakukan dilakukan, ini menghilangkan kebutuhan operator [16]. Contoh keberhasilan penggunaan kendali logika Fuzzy dalam pemrosesan suhu ruangan. Pengendali logika Fuzzy yang telah dibuat berhasil membangun sistem kendali dari model plant yang sulit diprediksi atau tanpa mencari model dari plant. kendali logika Fuzzy berhasil menjaga suhu dengan hasil pengujian respon didapatkan error sebesar 3,08\% [17]. Contoh keberhasilan lain penggunaan Fuzzy dalam mengendalikan suhu pada fermentasi susu yang hanya memiliki error $1,976 \%$ [18]. Pengendalian suhu pada purwarupa green house [19] dan pengendalian suhu pada mesin pengering contoh lain keberhasilan logika Fuzzy [20]. Merujuk dari beberapa referensi tersebut, kualitas proofing roti bisa dimaksimalkan menggunakan mesin proofing menggunakan pengendalian logika Fuzzy.

\section{METODOLOGI PENELITIAN}

Metode yang digunakan dalam penelitian ini adalah Riset dan Pengembangan (R\&D). Metode ini banyak digunakan dalam mengembangkan produk tertentu. Adapun tahapan dalam penelitian ini adalah dengan melakukan studi pra riset dengan mengamati mesin proof roti yang terdapat di pasaran saat ini masih menggunakan sistem konvensional dengan memanfaatkan saklar On/Off. Kemudian, dilakukan studi literatur yang berkaitan dengan dimensi dan bentuk mesin proofing roti yang akan di buat.

Tahap selanjutnya, dilakukan pemilihan ukuran mesin proofing dengan mempertimbangkan ukuran oven yang banyak dijual di pasaran. Tujuannya agar oven tersebut dapat dijadikan sebagai mesin proofing roti dengan penambahan komponen-komponen pendukung. Untuk menghasilkan pengukuran ruangan yang akurat, pengukuran suhu di dalam mesin proofing perlu diukur menggunakan sensor suhu yang diletakkan di tiga posisi, yaitu di posisi atas, tengah dan bawah. Tujuannya agar hasil pengukuran rata-rata dari ketiga posisi pengukuran ini mampu mewakili suhu ruangan di dalam mesin proofing. Untuk sensor kelembaban digunakan cukup satu sensor saja di bagian tengah, sebab uap yang dihasilkan bersifat menyebar ke seluruh ruang. Agar pemanas memiliki karakteristik cepat menghasilkan panas dengan waktu yang singkat, maka digunakan elemen pemanas yang berkapasitas 300 watt. Perancangan tata letak komponen dapat di lihat pada gambar 1 berikut di bawah ini:

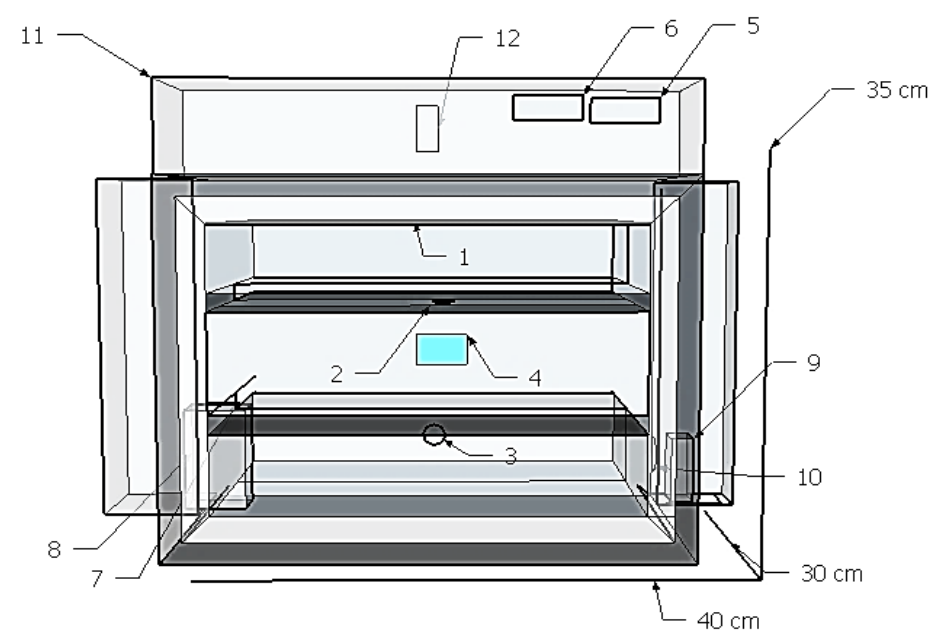

1. Sensor DS18B20

2. Sensor DS18B20

3. Sensor DS18B20

4. Sensor DHT 11

5. LCD indikator kendali suhu

6. LCD indikator kendali kelembaban

7. Evaporator (Penghasil uap)

8. Kipas untuk kelembaban

9. Heater (Pemanas)

10. Kipas untuk pemanas

11. Box komponen-komponen pendukung alat proofing.

12. Tombol Power ON/OFF

Gambar 1. Model tata letak komponen dan penempatan sensor terlihat dari depan.

Komponen pemanas, penghasil uap, kipas dikendalikan menggunakan sebuah mikrokontroller, mikrokontroller yang digunakan adalah Arduino. Semua komponen tersebut harus dapat dikendalikan dengan baik agar mampu menjaga suhu dan kelembaban di dalam proofer tersebut. Untuk itu diperlukan algoritma kendali untuk mengoptimalkan proses pengendalian suhu dan kelembaban. Dalam tulisan ini diusulkan 
algoritma yang digunakan menggunakan Logika Fuzzy. Untuk melihat bagaimana peran Logika Fuzzy dalam mengendalikan suhu dan kelembaban, hasil pengendalian suhu menggunakan Logika Fuzzy akan dibandingkan dengan pengendali konvensional, pengendali menggunakan pensaklaran ON/OFF. Beberapa tahapan dilakukan dalam penelitian ini sebagai berikut:

\subsection{Diagram Perancangan Keseluruhan Sistem}

Diagram perancangan sistem diilustrasikan seperti pada gambar 2. Berikut penjelasan fungsi setiap blok diagram pada gambar 2 berikut:

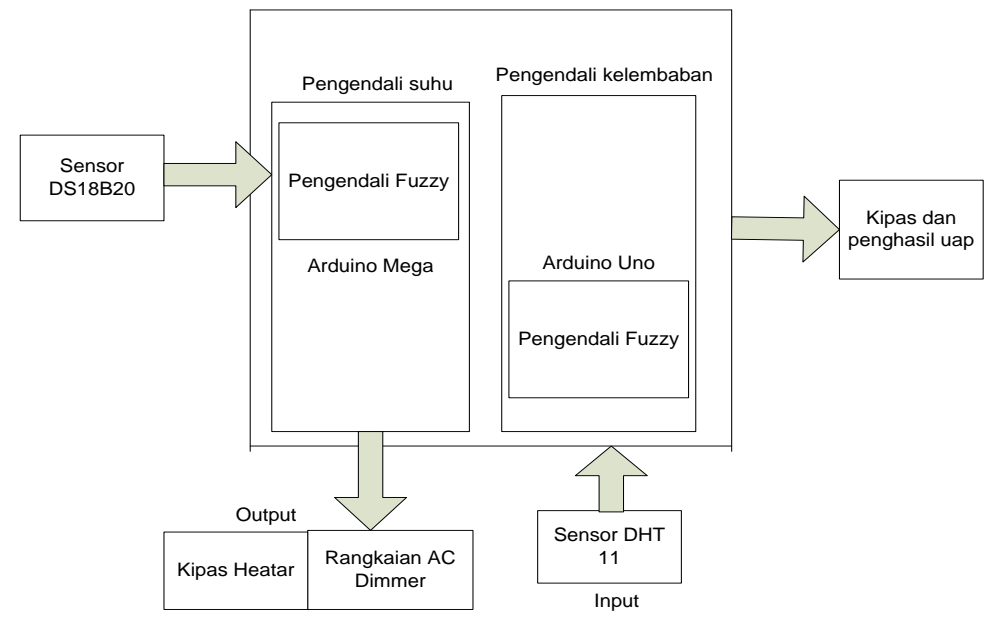

Gambar 2. Blok diagram perancangan sistem mesin proofing roti menggunakan logika Fuzzy

1. Fungsi sensor DS18B20 adalah sebagai sensor suhu yang digunakan untuk memberikan informasi suhu yang terukur pada mesin proofing pada Arduino Mega 2560.

2. Fungsi sensor DHT 11 adalah sebagai sensor kelembaban yang digunakan untuk memberikan informasi keadaan kelembaban yang terukur pada mesin proofing pada Arduino Uno.

3. LCD berfungsi untuk menampilkan suhu dan kelembaban yang terukur pada masing-masing sensor selama proses berlangsung.

4. Rangkaian AC Dimmer berfungsi sebagai driver pengatur tegangan masukan pada pemanas sehingga panas yang didapatkan dapat dikondisikan atau diatur sesuai dengan keluaran dari pengendali. Tegangan keluaran rangkaian AC Dimmer dapat diatur berdasarkan pemrograman pada Arduino Mega 2560.

5. Penghasil uap dan kipas pada sistem ini berfungsi untuk menghasilkan kelembaban pada sistem, kipas digunakan untuk mengatur banyak atau sedikitnya uap yang masuk pada mesin proofing

6. Pemanas berfungsi sebagai penghasil panas pada sistem dengan menggunakan elemen pemanas setrika listrik sebagai penghasil panas.

7. Pengendali logika Fuzzy berfungsi sebagai algoritma pengendali sistem agar mampu menghasilkan keluaran yang bisa menjaga nilai tatap pada set point.

8. Arduino Mega 2560 berfungsi sebagai perangkat keras pengendali yang sudah ditanamkan program untuk membaca sensor suhu dan mengendalikan suhu sistem menggunakan algoritma logika Fuzzy sebagai pengambil keputusan.

9. Arduino Uno berfungsi sebagai perangkat keras pengendali yang sudah ditanamkan program untuk membaca sensor kelembaban dan mengendalikan kelembaban sistem menggunakan algoritma logika Fuzzy sebagai pengambil keputusan.

\subsection{Perancangan Logika Fuzzy pada Kendali Suhu}

Logika Fuzzy memiliki kemampuan mengatasi dinamika proses yang relatif rumit dan kompleks. Logika Fuzzy mampu menyelesaikan permasalahan pengendalian tanpa mengetahui model matematika seperti pada logika konvensional. Pada kendali menggunakan logika Fuzzy, informasi dari variabel numerik diubah menjadi variabel linguistik. Untuk itu kita perlu mendefinisikan variabel masukan dan keluaran menjadi persamaan matematisnya. Besarnya variabel tegangan keluaran yang dihasilkan akan sebanding dengan masukan berupa variabel error dan variabel delta error dan rules (aturan) yang akan kita buat. Variabel error didefinisikan sebagai selisih antara nilai suhu terukur terhadap dengan nilai set point, sedangkan variabel derror didefinisikan sebagai selisih nilai error sekarang terhadap dengan nilai error sebelumnya. 


$$
\begin{aligned}
& \text { error }=\text { Suhu Set point }- \text { Suhu Terukur } \\
& \text { derror }=\mid \text { Error }_{\mathrm{n}}|-| \text { Error }_{\mathrm{n}-1} \mid
\end{aligned}
$$

Untuk mendapatkan nilai error dan derror, maka dilakukan pengukuran pada pembacaan sensor pada sistem, setelah data-data didapatkan tahapan selanjutnya adalah melakukan tahapan fuzzifikasi, pembentukan rules base dan tahapan defuzzifikasi.

Tahap awal adalah menentukan fungsi keanggotaan untuk setiap masukan error dan derror. Masukan pengendali logika Fuzzy yang berupa error didapat dari hasil selisih antara set point dan suhu keluaran sistem. Berdasarkan referensi, rentang suhu proses proofing yang baik berkisar $35-40{ }^{\circ} \mathrm{C}$ [12], Sehingga pada penelitian ini set point ditetapkan sebesar $35{ }^{\circ} \mathrm{C}$, dengan batas minimal $32{ }^{\circ} \mathrm{C}$ dan batas maksimal $38{ }^{\circ} \mathrm{C}$. Berdasarkan ketetapan ini, maka error batas bawah $-3^{\circ} \mathrm{C}$ dan batas atas $+3^{\circ} \mathrm{C}$. Dengan penetapan error ini diharapkan nilai pengendalian suhu tidak keluar batas rentang suhu ini. Berdasarkan penetapan ini, maka fungsi keanggotaan masukan untuk variabel error tergambar seperti pada gambar 3. Fungsi keanggotaan error untuk suhu, dibagi menjadi 3 himpunan Fuzzy, yaitu EN (Error Negatif), N (Nol) dan EP (Error Positif).

Variabel derror merupakan representasi dari perubahan error. Semakin kecil rentang derror semakin sensitif terhadap respons keluaran, tapi terlalu sensitif juga memberikan efek keluaran berupa osilasi. Agar sistem tidak terlalu sensitif, tapi masih cukup menjaga perubahan error, nilai rentang derror ditetapkan tidak terlalu kecil namun juga tidak terlalu besar. Nilai derror ditetapkan maksimal $-1{ }^{\mathrm{s}} \mathrm{C}$ dan $+1{ }^{\circ} \mathrm{C}$ dengan tingkat resolusi $0,5{ }^{\circ} \mathrm{C}$. Dari ketetapan ini fungsi keanggotaan derror suhu ada 5 anggota seperti tergambar pada gambar 3. Fungsi keanggotaan masukan ini dibagi menjadi 5 himpunan Fuzzy, yaitu KB (Kurang Besar), KK (Kurang Kecil), Z (Zero), PK (Positif Kecil) dan PB(Positif Besar).

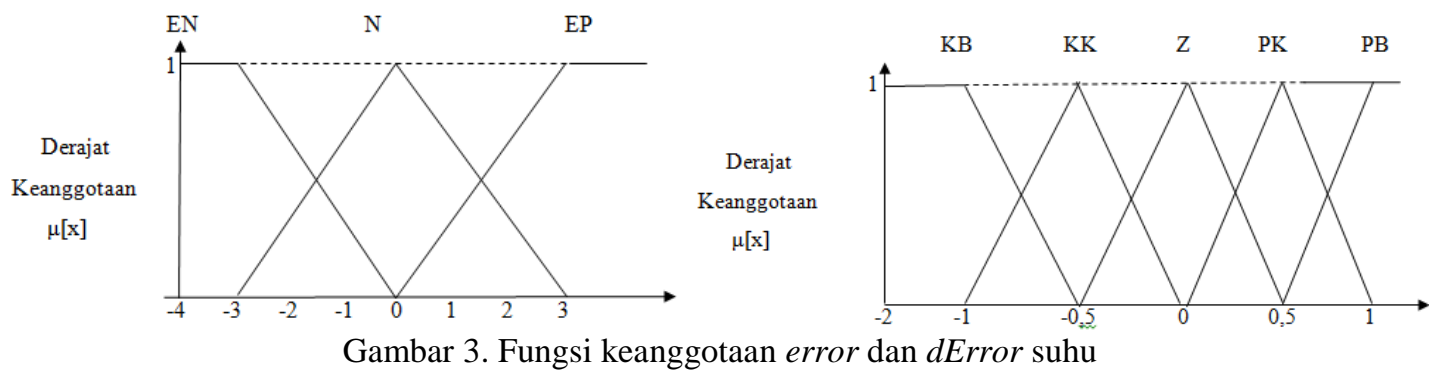

Variabel keluaran pada kendali suhu adalah sinyal PWM yang masuk ke AC Dimmer. Rangkaian AC Dimmer berfungsi untuk mengatur tegangan yang masuk pada pemanas, nilai tegangan ini mempengaruhi panas yang dihasilkan oleh elemen pemanas. Pemilihan nilai tegangan keluaran pada kendali logika Fuzzy suhu berdasarkan hasil dari penelitian pendahuluan didapatkan hasil variasi tegangan keluaran sebesar $0 \mathrm{~V}, 50$ V, $150 \mathrm{~V}$ dan 220 VAC. Dari data ini, fungsi keanggotaan keluaran ini dibagi menjadi 4 himpunan keanggotaan Fuzzy, yaitu KB (Kurangi Besar), KK (Kurangi Kecil), PS (Pas), dan T (Tambah). Nilai keluaran dipilih single tone (crips) untuk memudahkan melakukan Fuzzifikasi. Perangkat keras pengendali yang digunakan tidak mampu melakukan perhitungan matematika grafis, sehingga digunakan fungsi keanggotaan keluaran berupa bilangan crips.

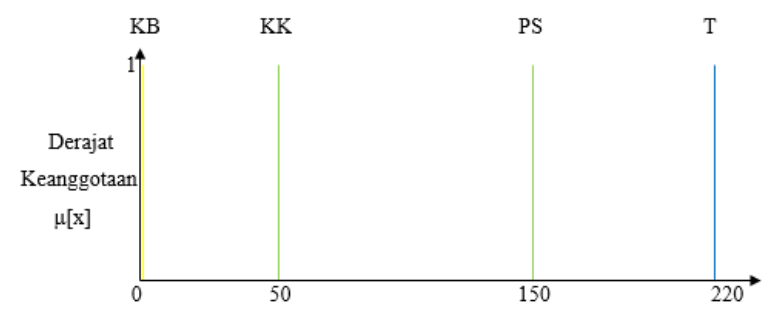

Gambar 4. Fungsi Keanggotaan keluaran suhu (VAC)

Pemetaan aturan/ rules dalam penentuan keputusan berdasarkan hubungan antara masukan variabel error dan derror dengan variabel keluaran. Hubungan ini ditentukan berdasarkan pengalaman dengan memilih pendekatan yang mampu mengurangi error. Metode inferensi yang dipakai adalah Sugeno, dan pendekatan pengambilan keputusan (inferensi) yang digunakan dalam pemrograman ini adalah metode Min-Max. Seperti halnya dengan proses Fuzzifikasi, ketika menentukan rules base dilakukan secara intuitif dan berdasarkan pengamatan. Rules base yang digunakan pada penelitian ini seperti yang tertera pada tabel 1 berikut: 
Tabel 1 Rules base pengendali logika Fuzzy

\begin{tabular}{cccc}
\hline Derror & Error & Nol (N) & \multirow{2}{*}{ Error Positif (EP) } \\
\hline Kurang Besar (KB) & Kurangi Besar (KB) & Kurangi Besar (KB) & Kurangi Kecil (KK) \\
Kurang Kecil (KK) & Kurangi Besar (KB) & Kurangi Besar (KB) & Kurangi Kecil (KK) \\
Zero (Z) & Kurangi Besar (KB) & Kurangi Besar (KB) & Pas (P) \\
Positif Kecil (PK) & Kurangi Besar (KB) & Kurangi Kecil (KK) & Pas (P) \\
Positif Besar (PB) & Tambah (T) & Kurangi Kecil (KK) & Tambah (T) \\
\hline
\end{tabular}

\subsection{Perancangan Logika Fuzzy pada Kendali Kelembaban}

Berdasarkan referensi, rentang kelembaban yang baik berada pada kelembaban relatif berkisar antara $80 \%$ hingga $90 \%$ [12][13]. Oleh sebab itu, set point kelembaban ditetapkan sebesar $85{ }^{\circ} \mathrm{C}$. Waktu respon waktu sensor dalam mengukur kelembaban relatif lebih lambat dari dibandingkan pengukuran suhu, sehingga rentang batas atas dan bawah dibuat lebih lebar namun masih dalam rentang yang diperbolehkan. Untuk kelembaban ditetapkan batas maksimal sebesar $90 \%$ dan batas minimal $80 \%$. Berdasarkan ketetapan ini batas error bawah sebesar $-5 \%$ dan batas atas sebesar $+5 \%$. Dari ketetapan ini fungsi keanggotaan masukan error kelembaban dibagi menjadi 3 himpunan Fuzzy, yaitu KL (Kurang Lembab), P (Pas) dan SL (Sangat Lembab).

Pada pengaturan kelembaban, sensor kelembaban memiliki respon waktu yang relatif lambat, sehingga fungsi keanggotaan derror kelembaban tidak bisa dibuat terlalu kecil. Nilai derror ditetapkan sama seperti error, maksimal -5\% dan 5\%. Dari hasil penelitian pendahuluan, ternyata penurunan kelembaban lebih mudah terjadi dibandingkan peningkatan kelembaban, sebab ketika proses pengurangan kelembaban, kipas membuang udara lembab yang ada di dalam mesin proofer. Oleh sebab itu, untuk mengatasi hal ini, nilai derror ditambah satu untuk perubahan error negatif dengan rentang tipis, tujuannya agar ketika penurunan kelembaban kurang dari 5\%, sistem cepat merespons untuk menambahkan uap air. Dari ketetapan ini fungsi keanggotaan derror kelembaban dibagi menjadi 4 himpunan Fuzzy, yaitu NB (Negatif Besar), NK (Negatif Kecil), N (Nol) dan P (Positif).

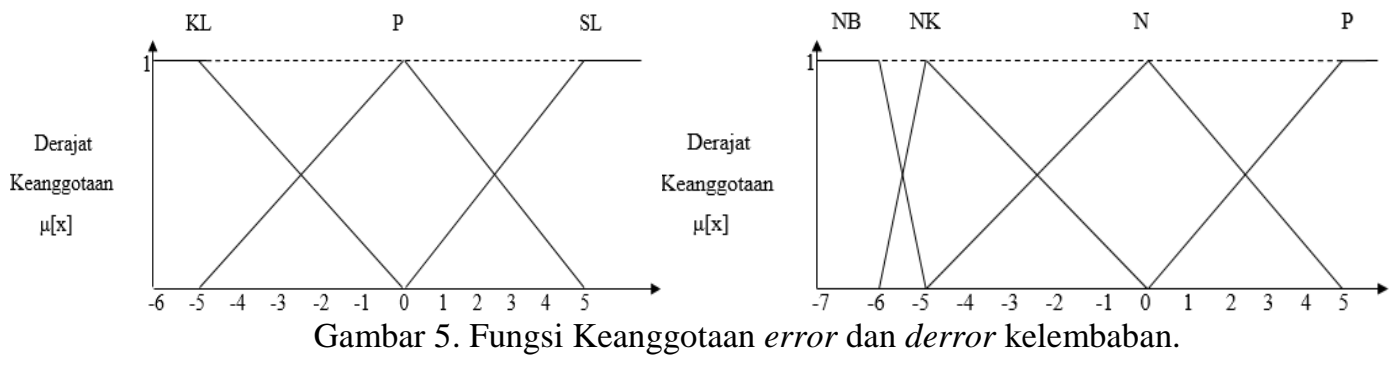

Variabel keluaran pada kendali suhu adalah PWM yang berfungsi untuk mengendalikan driver kipas, setelah dilakukan percobaan dengan mengubah nilai PWM pada driver kipas. Nilai keluaran kendali Fuzzy kelembaban didapatkan dari hasil penelitian awal. Setelah dilakukan percobaan maka didapatkan nilai PWM yaitu 0, 30, 100 dan 225 yang digunakan sebagai masukan driver kipas. Pada variabel keluaran pada kelembaban, data yang dimiliki adalah 0, 30, 100 dan 225 dengan demikian pada variabel ini dibagi menjadi 4 himpunan Fuzzy, yaitu SL (Sangat Lambat), L (Lambat), S (Sedang), K (Kencang).

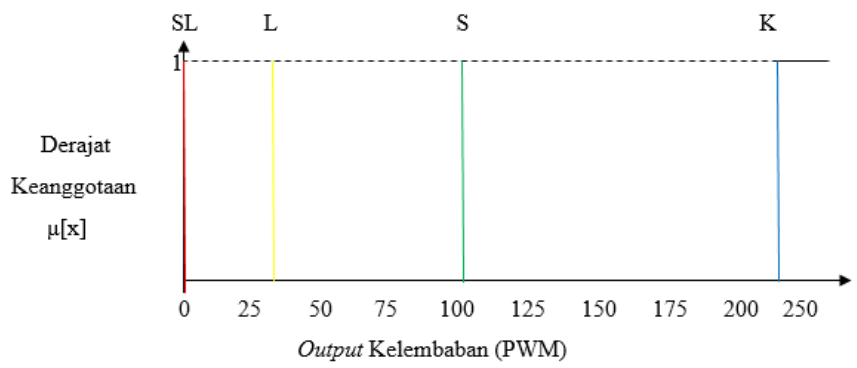

Gambar 6. Output Kelembaban (PWM)

Berdasarkan data penelitian pendahuluan dan pengamalan, pemetaan rulesuntuk kelembaban ditetap seperti pada tabel 2 berikut: 
Tabel 2 Rules base pengendali Fuzzy

\begin{tabular}{cccc}
\hline Eerror & $\begin{array}{c}\text { Kurang Lembab } \\
(\text { KL) }\end{array}$ & Pas (P) & Sangat Lembab (SL) \\
\hline Negatif Besar (NB) & Sangat Lambat (SL) & Sangat Lambat (SL) & Kencang (K) \\
Negatif Kecil (NK) & Sangat Lambat (SL) & Sangat Lambat (SL) & Sangat Lambat (SL) \\
Nol (N) & Sangat Lambat (SL) & Sangat Lambat (SL) & Sedang (S) \\
Positif (P) & Sedang & Sangat Lambat (SL) & Kencang (K) \\
\hline
\end{tabular}

\subsection{Konfigurasi Komponen-komponen}

Perancangan skema pengkabelan menggunakan simulasi ISIS Professional 7, dalam perancangan pengkabelan ini dibutuhkan komponen-komponen pendukung, adapun komponen dalam perancangan pengkabelan adalah tiga sensor suhu DS18B20, Sensor DHT 11, mikrokontroler yang digunakan yaitu Arduino Mega dan Arduino Uno, dua LCD 2 x 16, rangkaian ACDimmer, driver kipas L293D, pemanas dan evaporator. Pengkabelan pada sistem ini terbagi dua bagian yaitu pengkabelan kendali suhu dan pengkabelan kendali kelembaban.

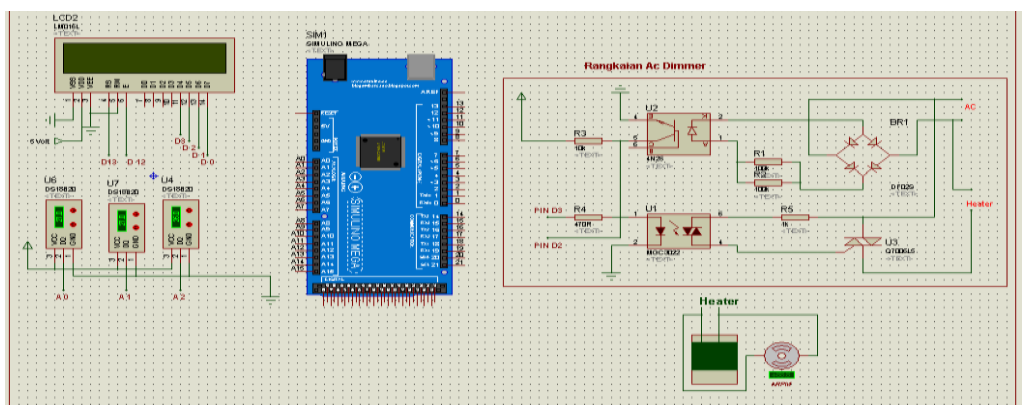

Gambar 7 Konfigurasi pin input output komponen sistem kendali suhu pada mesinproofing.

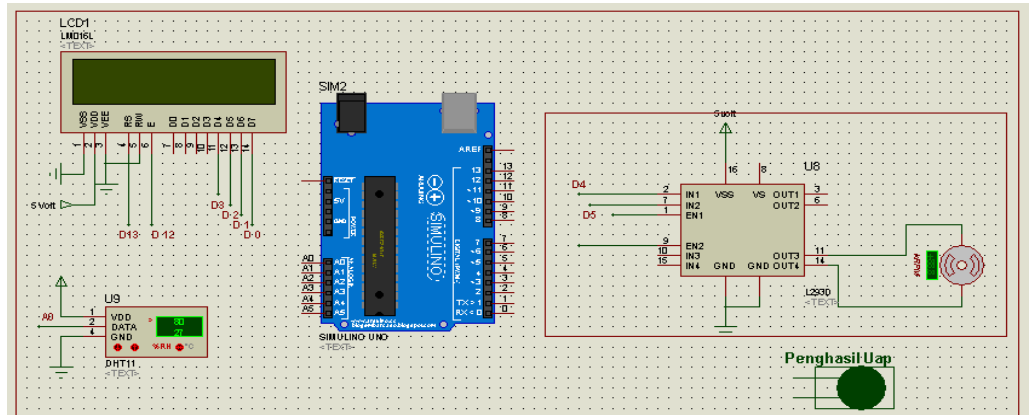

Gambar 8 Konfigurasi pin input output komponen sistem kendali kelembaban pada mesinproofing

\section{HASIL DAN PEMBAHASAN}

Perangkat kotak mesin proofing roti pada gambar 9 terdiri dari 1 elemen pemanas yang dilengkapi dengan kipas yang berfungsi menyebarkan panas dan 1 penghasil uap yang dilengkapi kipas untuk menyebarkan uap ke dalam kotak proofing. Elemen pemanas terdapat pada sebelah kanan kotak mesin proofing roti dan penghasil uap terletak pada sebelah kiri.

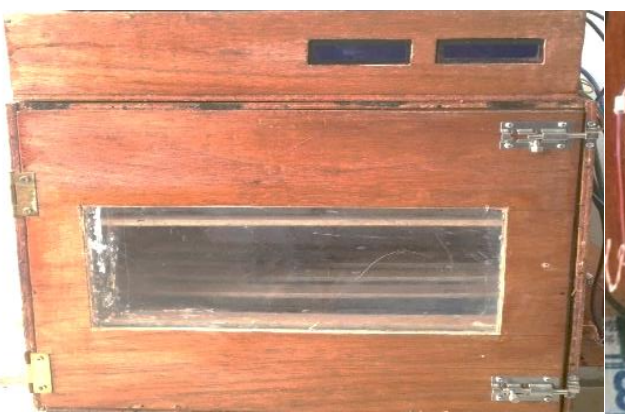

(a)

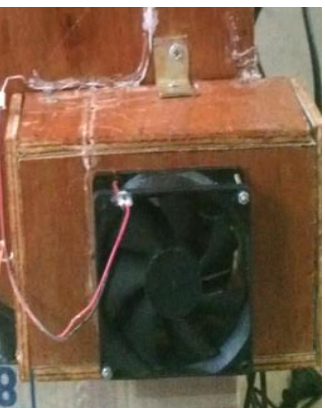

(b)

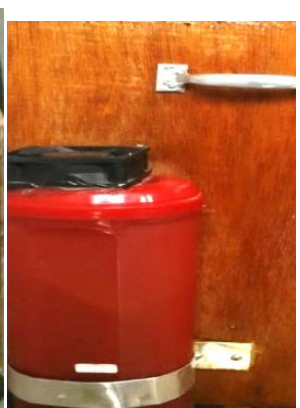

(c)

Gambar 9.(a) Hasil Pembuatan Mesin proofing Tampak dari Depan. (b) kipas. (c) evaporator 


\subsection{Hasil Pengujian Mesin Proofing Roti Kendali Fuzzy pada Kondisi Kosong}

Pengujian mesin proofing roti dilakukan untuk mengetahui apakah menggunakan kendali logika Fuzzy memberikan dampak yang signifikan dibandingkan pengendali konvensional. Pengujian mesin proofing roti dilakukan dengan menggunakan kendali ON/OFF dan kendali logika Fuzzy yang ditanamkan pada arduino yang berfungsi untuk mengetahui perbandingan kestabilan sistem mesin proofing roti. Pengujian pertama mesin proofing roti dioperasikan dengan kendali ON/OFF pada kondisi kosong. Pengujian kedua mesin proofing roti dioperasikan dengan kendali logika Fuzzy dalam kondisi kosong.

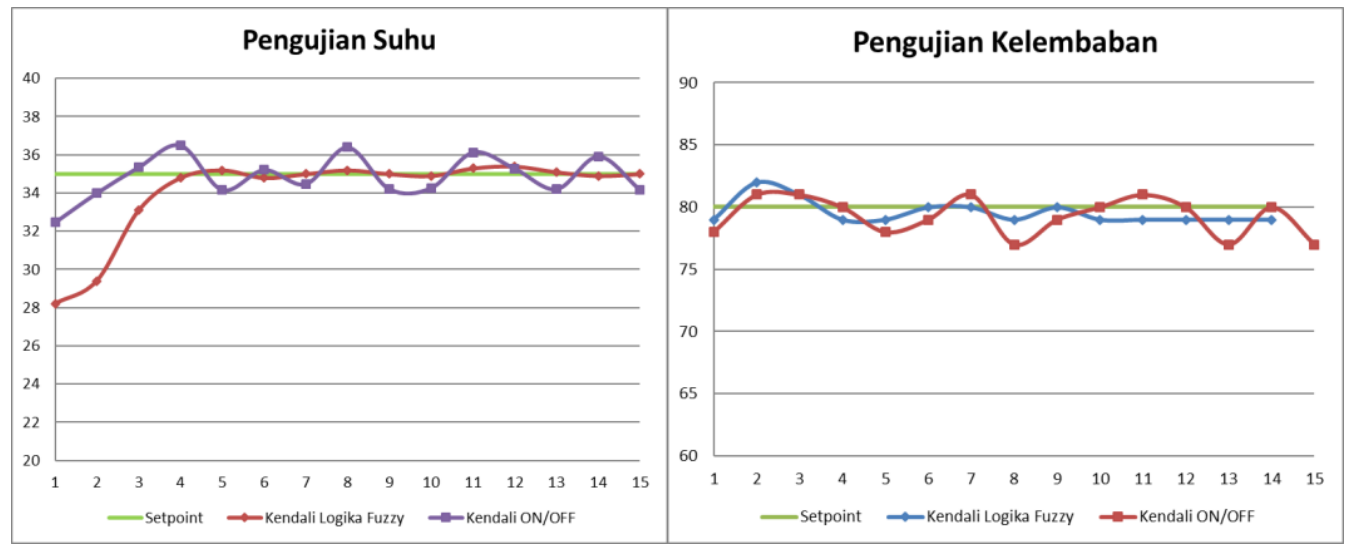

Grafik 10. Hasil Pengujian suhu dan kelembaban pada mesin proofing roti menggunakan Kendali ON/ OFF dan kendali Logika Fuzzy

Dari perbandingan antara hasil pengujian menggunakan kendali ON/OFF dengan kendali logika Fuzzy terlihat bahwa pengaturan suhu menggunakan Logika Fuzzy didapatkan hasil yang lebih baik dibanding kendali ON/OFF. Kendali suhu menggunakan Logika Fuzzy didapatkan error rata-rata terhadap set poin sebesar 0,429\% sedangkan kendali suhu menggunakan menggunakan kendali ON/OFF memiliki error ratarata sebesar 2,36\%. Fluktuasi suhu pada logika fuzzy relatif stabil. Begitu juga hasil yang didapatkan pada pengujian kelembaban, hasil yang didapatkan menggunakan kendali logika Fuzzy dibandingkan kendali ON/OFF didapatkan hasil yang relatif hampir sama, namun secara umum tetap didapatkan hasil yang lebih baik menggunakan kendali Logika Fuzzy. Kendali kelembaban menggunakan Logika Fuzzy didapatkan ratarata error sebesar $0,94 \%$, sedangkan menggunakan kendali ON/OFF error rata-rata sebesar 1,56\%.

\subsection{Hasil Pengujian Mesin Proofing Roti Kendali Fuzzy pada Kondisi Fermentasi Adonan Roti}

Pengujian mesin proofing roti dilakukan untuk mengetahui apakah mesin proofing roti ketika berisi muatan berupa adonan roti hasilnya lebih bagus dibandingkan ketika mesin proofing kosong tanpa muatan. Pada pengujian ini,mesin proofing roti dioperasikan dalam kondisi ada adonan roti atau ada beban pemanasan.Pengujian dilakukan sebanyak 5 kali lalu hasilnya di rata-ratakan dan dimasukkan ke dalam grafik.

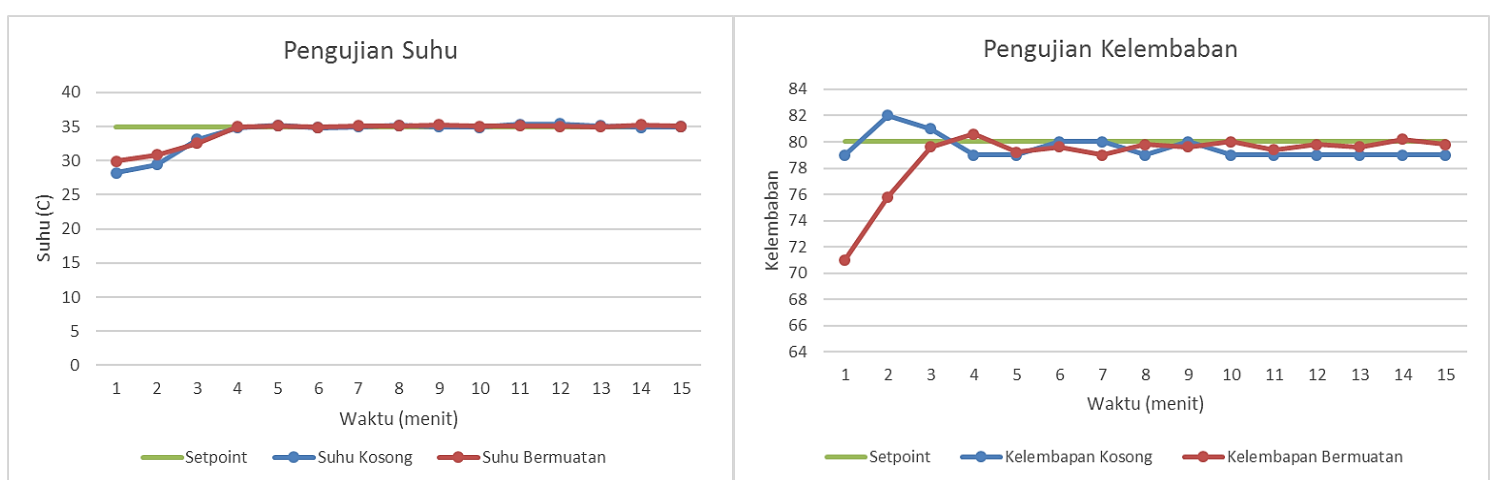

Grafik 11 Hasil Pengujian suhu dan kelembaban antara mesin proofing bermuatan adonan roti dengan mesin proofing ketika kosong menggunakan Kendali Logika Fuzzy

Hasil grafik menunjukkan bahwa terdapat selisih error rata-rata antara pengujian suhu dan kelembaban ketika mesin proofing kosong dan ketika terdapat muatan, yaitu sebesar 0,024\% untuk suhu dan 0,015\% untuk kelembabannya. 


\section{KESIMPULAN}

Dari hasil pengujian yang sudah dilakukan, didapatkan bahwa pengendalian suhu dan kelembaban pada mesin proofing roti menggunakan logika Fuzzy mampu memberikan hasil yang baik dibandingkan pengendali konvensional (kendali ON/OFF). Hal ini menunjukkan peran dari Logika Fuzzy untuk meredam kenaikan suhu dan kelembapan setelah mencapai set poin, dan mampu menjaga suhu dan kelembapan tidak turun terlalu jauh dari set poin. Bahkan ketika pengujian menggunakan mesin proofing yang sudah diberi muatan, hasil yang didapatkan relatif sama dibandingkan ketika kosong.

\section{UCAPAN TERIMA KASIH}

Penulis mengucapkan terima kasih kepada masyarakat kecamatan Pangean, Kabupaten Kuantan Singingi yang telah bersedia menjadi sumber data pada pengujian alat. Tidak lupa pula ucapan terima kasih kepada Imam Santoso dan Fakultas Sains dan Teknologi UIN Suska Riau yang sudah mensuport penelitian ini.

\section{REFERENSI}

[1] Kementerian Perdagangan. Laporan Akhir Analisis Dinamika Konsumsi Pangan Masyarakat Indonesia. Pusat Kebijakan Perdagangan Dalam Negeri. Badan Pengkajian Dan Pengembangan Kebijakan Perdagangan Kementerian Perdagangan. 2013.

[2] CIMB-Principal Asset Management.Baking The Prosperity. Weekly Indo Perspective. 2015.

[3] Surliyadin. Penerapan Pemasaran Berbasis Pengalaman dan Ekuitas Merek Dalam Menciptakan Kepercayaan Pelanggan Pada J.Co Donuts \& Coffee - Cihampelas Walk Bandung. Skripsi Universitas Widyatama. 2014

[4] Kementerian Pertanian. Statistik Konsumsi Pangan. Pusat Data Dan Sistem Informasi Pertanian. Kementerian Pertanian. 2015.

[5] BPS. Indonesia Population Projection 2010-2035. Badan Pusat Statistik. 2013

[6] Rosell, Cristina M.. Flour and Breads and their Fortification in Health and Disease Prevention. Chapter 1 : The Science of Doughs and Bread Quality. 2011. Elsevier Inc.

[7] Rosell, Cristina M, Concha Collar. Effect of temperature and consistency on wheat dough performance. Internasional Journal of Food Science and Technology 2009, 44, 493-502.

[8] Byong H. Lee. Fundamentals of Food Biotechnology. Wileyblackwell. 2015.

[9] Syarbini, Husin. Referensi Komplet A-Z Bakery: Fungsi Bahan, Proses Pembuatan Roti, Panduan Menjadi Bakepreneur. Metagraf, Tiga Serangkai. 2016

[10] Koswara, Sutrisno. 2009. Teknologi Pengolahan Roti. eBook Pangan.

[11] Cauvain, Stanley P. Baking Problems Solved (Second Edition). Woodhead Publishing Series in Food Science, Technology and Nutrition. 2017, Pages 153-234

[12] Carl, Batt, Richard Robinson. Bread from Wheat Flour. Encyclopedia of Food Microbiology, Elsevier Ltd. 2014

[13] Huang, Sidi, Diane Miskelly. Laboratory Preparation and Evaluation of Steamed Bread. Woodhead Publishing Series in Food Science, Technology and Nutrition. Pages 109-137.2016,

[14] Perrot, N. and C. Baudrit. Intelligent Quality Control Systems in Food Processing Based on Fuzzy Logic. Woodhead Publishing Limited, 2013

[15] Delgado, Antonio, Cornelia Rauh, Jinyoung Park and YouJin Kim, Frauke Grob and Lucia Diez. Artificial Neural Networks: Applications in Food Processing. Elsevier Inc. 2016

[16] Davidson V. J., K. D. Smith. A Fuzzy Controller for a Batch Cooking Process. Journal of Food Engineering 24. Elseview Sience. 1994)

[17] W, Diyan Agung., Purwanto, Bambang Siswojo.Aplikasi Pengendali Suhu Ruangan Dengan Kontroler Logika Fuzzy Berbasis Mikrokontroler AVR-Atmega 328. Skripsi Jurusan Teknik Elektro Fakultas Teknik Universitas Brawijaya. 2013.

[18] Dicarara, Marina. Susu Dengan Kontrol Logika Fuzzy Berbasis Mikrokontroler Arduino Mega. Skripsi Jurusan Teknik Elektro. Fakultas Teknik Universitas Brawijaya. 2014

[19] Azizi, Mulkan, Sumardi, Munawar Agus R. Perancangan Sistem Pengendalian Suhu Pada Prototype Green House Berbasis Kendali Logika Fuzzy. TRANSIENT, VOL.3, NO. 4, Desember 2014, ISSN: 2302-9927, 604 
[20] Satria, Dhimas, Erny Listijorini, Muhammad Ramdhan Nurghodan. Design of Temperature Control System on Hybrid Drying Machine using Fuzzy Logic Method. Jurnal Ilmiah Rekayasa Pertanian dan Biosistem, Vol.3, No. 2 September 2015.

\section{BIBLIOGRAFI PENULIS}

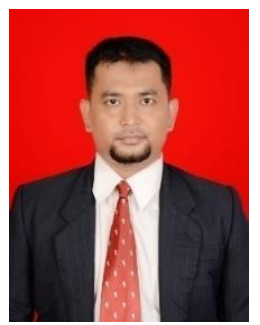

Aulia Ullah, ST.,, M.Eng yang biasa dipanggil Aul, Asli orang Air Molek. Lulus dari program Studi Fisika Teknik Universitas Gadjah Mada Tahun 2008.Lalu penulis melanjutkan Studi S2 di Magister Sistem Teknik di Universitas Gadjah mada selesai tahun 2012. Saat ini penulis adalah Dosen di program Studi Teknik Elektro Fakultas Sains dan Teknologi UIN Sultan Syarif Kasim Riau. Bidang keahlian yang ditekuni Otomasi Industri dan sistem kendali cerdas.

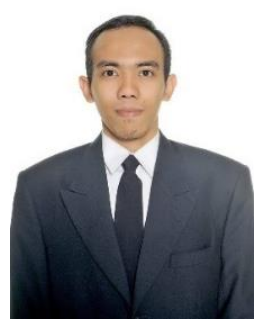

Oktaf Brillian Kharisma ST., MT., yang akrab dipanggil Oktaf. Lulus dari Teknik Elektro Universitas Jember tahun 2008. Tahun 2011 penulis melanjutkan Studi S2 di Computer Engineering Institut Teknologi Bandung. Saat ini penulis adalah Dosen di program Studi Teknik Elektro Fakultas Sains dan Teknologi UIN Sultan Syarif Kasim Riau. Bidang keahlian yang ditekuni adalah Robotika dan Sistem embedded

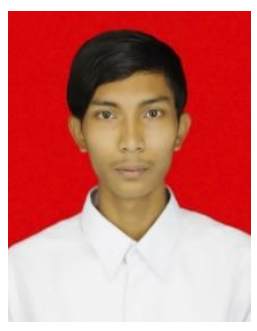

Imam SantosoST, yang akrab dipanggil Imam, lahir di Pati pada tanggal 28 September 1993. Penulis merupakan anak pertama dari pasangan suami istri Supadi dan Warsini yang beralamat di Desa Sako Kec Pangean, Kab Taluk Kuantan Kota Pekanbaru.Kuliah di Teknik Elektro UIN Suska Riau masuk tahun 2013 dan menyelesaikan kuliah tahun 2018. 